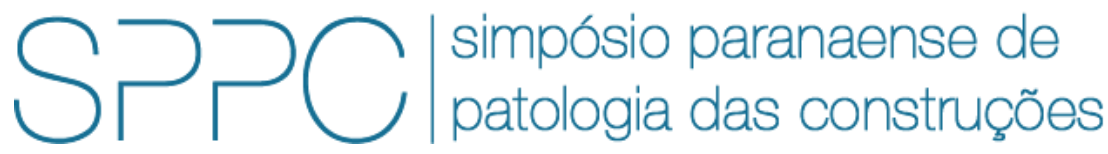

ISSN 2526-7248 artigo 2SPPC1030, pp. 365-370, 2017

\title{
Avaliação do potencial de corrosão de telas metálicas utilizadas para reforço de revestimentos argamassados externos
}

\author{
Emmanuel Inácio da Silva ${ }^{1}$, Angelo Just da Costa e Silva² \\ ${ }^{1}$ Graduando em Engenharia Civil, Uninassau, emmmanuel.is@hotmail.com \\ 2 Doutor em Engenharia Civil, Universidade de Pernambuco, angelo@tecomat.com.br
}

\begin{abstract}
Resumo: O revestimento externo de uma edificação é o primeiro sistema a sofrer com a inscidência da chuva, altas temperaturas e demais intempéries trazidas com a ação do vento. Paredes externas que apresentam emboço com espessura acima do determinado em norma em vários pontos da fachada provocam tensões elevadas entre o substrato e o revestimento, se fazendo necessária a aplicação de telas metálicas de reforço. A depender da camada de cobrimento das telas e da posição em que está sendo aplicada, o material pode sofrer corrosão e provocar deslocamento do revestimento. Esse trabalho tem o objetivo de avaliar o potencial de corrosão das telas eletrosoldadas aplicadas entre as camadas do emboço com a função de garantir a aderência e evitar manifestações patológicas. A obra analisada foi uma torre de um condomínio localizado no litoral da Região Metropolitana do Recife, onde o meio ambiente se apresenta mais agressivo e favorece a corrosão. Para o ensaio foram utilizados eletrodos de cobre-sulfato de cobre, método proposto pela ASTM C876. No período em que o revestimento foi analisado estava com 78 dias de cura. As médias, encontradas através da leitura de 10 pontos nas fachadas leste e oeste, foram $12,8 \mathrm{mV}$ e $7,3 \mathrm{mV}$ respectivamente. A partir desses dados foi possível concluir que nessas condições as telas só apresentaram $10 \%$ de probabilidade de corrosão, mas que se faz necessário um acompanhamento mais assíduo, quando o revestimento estiver com mais idade, para um melhor prognóstico.
\end{abstract}

Palavras-chave: Controle, Qualidade, Indicador, Patologia.

Abstract: The outer shell of a building is the first system to suffer with an insidence of rain, high temperatures and other inclement weather brought with a wind action. External walls that have paving with thickness above that determined in standard in several points of the facade cause high tensions between the substrate and the coating, are making an application of reinforcing metallic screens. Depending on the cover layer of the screens and the position in which it is being applied, the material may suffer corrosion and lead to displacement of the coating. This work has the objective of evaluating the corrosion potential of the screens and the applications applied as layers of the plaster with a function of guaranteeing adherence and avoiding pathological manifestations. A work analyzed for a condominium tower located on the coast of the Metropolitan Region of Recife, where the environment is more aggressive and favors corrosion. Copper-copper sulphate electrodes, as proposed by ASTM C-876, were used for the test. In the period in which the treatment was analyzed with 78 days of cure. As averages, found by reading 10 points on the east and west façades, they were $12.8 \mathrm{mV}$ and $7.3 \mathrm{mV}$ respectively. From concrete data, it can be concluded that the working conditions are as follows: $10 \%$ probability of corrosion, but a more frequent follow-up is necessary, when the coating is older, for a better prognosis.

Keywords: Control, Quality, Indicator, Pathology. 


\section{Introdução}

De acordo com as premissas da ABNT NBR 13755 [1], o revestimento externo argamassado, além do desempenho estético, têm a função de isolamento e proteção da edificação no que diz respeito às ações da chuva, umidade e demais ações das intempéries através do vento que podem afetar a durabilidade do sistema.

Além das ações externas, o revestimento externo pode sofrer com alterações originadas da própria edificação [2], quais sejam: movimentações higroscópicas e térmicas do revestimento, da base ou substrato.

Dentre as manifestações patológicas nos revestimentos externos, Bauer [3] afima que os descolamentos do emboço se apresentam com mais recorrência, decorrentes de diversos fatores, a saber: produtos não hidratados corretamente, má qualidade dos insumos, preparo inadequado da argamassa ou falha na aplicação do emboço e dos serviços predecessores.

Ainda explanando a respeito dos pontos levantados por Bauer [3], ele explica que o emboço externo com espessura acima de $2 \mathrm{~cm}$ em grandes áreas da fachada se faz necessária a aplicação de telas metálicas galvanizadas para reforço, devido à elevada tensão entre o substrato e o revestimento. Porém, a ABNT NBR 13755 [1] apresenta uma folga maior quanto à necessidade de reforço desse sistema, tolerando até $2,5 \mathrm{~cm}$ de revestimento, e ressalta a importância do recobrimento da tela para protegê-la de possível corrosão.

Entende-se como corrosão a deterioração de um material metálico por ações químicas ou eletroquímicas do meio ambiente associada ou não a esforços mecânicos [4].

O potencial de corrosão (EconR) do aço [5] é determinado pelas leituras das medidas eletroquímicas obtidas através do eletrodo de referência de cobre-sulfato de cobre acoplado ao multímetro.

A ASTM C-876 não estabelece parâmetros para a avaliação do potencial de corrosão do aço galvanizado e não existe, atualmente, normalização disponível para essa situação [6]. Dito isso, serão utilizados os critérios do aço carbono (Tabela 1).

Tabela 1: Critério de avaliação dos resultados das medidas eletroquímicas

\section{Potencial de corrosão (EconR) relativo ao eletrodo de referência de cobre-sulfato de cobre}

$$
\begin{gathered}
\text { Mais negativo que }-350 m v \\
\text { De }-200 m v \text { a }-350 m v \\
\text { Mais positivo que }-200 \mathrm{Mv}
\end{gathered}
$$

\section{Probabilidade de corrosão}

$90 \%$
Incerteza
$10 \%$

Segundo Sabbatini et al. [7], revestimentos com espessuras maiores melhoram a capacidade de absorver deformações, mas também podem comprometer a aderência. De qualquer forma, isso deve ser estabelecido e controlado através de um projeto executivo que oriente quanto à posição das telas de reforço e determine 
espessuras mínimas para o revestimento externo a depender da base em que será aplicado (Tabela 2).

Tabela 2: Espessura mínimas nos pontos críticos

\begin{tabular}{cc}
\hline Tipo de base & Espessura mínima (mm) \\
\hline Estrutura de concreto em pontos & 10 \\
Alvenaria em pontos localizados & 15 \\
Vigas e pilares em regiões extensas & 15 \\
Alvenarias em regiões extensas & 20 \\
\hline
\end{tabular}

Além dos esforços solicitados à base e se fazer necessária a colocação da tela metálica de reforço para garantir a aderência do sistema, espessura acima de $5 \mathrm{~cm}$ favorecem o surgimento de fissuras derivadas da retração por secagem e se não respeitado o prazo mínimo de 7 dias entre as camadas de regularização e acabamento, facilita a percolação da água e as ações das intempéries [3-7], originando manifestações patológicas já citadas nesse trabalho.

O ensaio de resistência de aderência $(\mathrm{Ra})$ de revestimentos de paredes é normalizado pela ABNT NBR 13749, e determina que, após 28 dias de cura da argamassa aplicada, o sistema atenda aos requisitos listados na Tabela 3 [8].

Tabela 3: Limites de resistência de aderência à tração $(\mathrm{Ra})$ para emboço externo

\begin{tabular}{ccc}
\hline Local & Acabamento & Ra (MPa) \\
\hline \multirow{2}{*}{ Parede externa } & Pintura ou base para reboco & $\geq 0,30$ \\
& Cerâmica & $\geq 0,30$ \\
\hline
\end{tabular}

\section{Objetivo}

Esse trabalho tem o objetivo de analisar o potencial de corrosão das telas metálicas eletrosoldadas galvanizadas utilizadas para reforço do revestimento argamassado externo em casos em que a espessura estabelecida em norma é ultrapassada.

\section{Metodologia}

Para elaboração desse trabalho foi realizado uma revisão bibliográfica a partir de livros especializados, artigos técnicos e científicos que abordam os temas voltados para manifestações patológicas em revestimentos externos argamassados. Os parâmetros das normas nacionais e internacionais também foram estudados a fim de esclarecer dúvidas frequentes e nortear os ensaios realizados.

A obra estudada é um condomínio residencial composto por 7(sete) torres de 8(oito) pavimentos cada uma, com 4 apartamentos por andar. São 4 opções de planta que variam de $109 \mathrm{~m}^{2}$ a $195 \mathrm{~m}^{2}$ e um total de 224 unidades. As edificações estão localizadas na Região Metropolina de Recife (RMR), próximas ao litoral, de forma que o ambiente se torna agressivo devido à quantidade de sais atuantes nos revestimentos. Dentre as torres disponibilizadas para a realização do estudo, a Torre 
7 foi escolhida pelo fato de a argamassa de revestimento apresentar mais de 28 dias de cura, na época em que o sistema foi avaliado. O emboço da fachada foi executado durante o período de janeiro a agosto de 2013.

Foi realizado o ensaio de avaliação do potencial de corrosão relativo ao eletrodo de cobre-sulfato de cobre, normalizado pela ASTM C-876 [5] nas fachadas leste e oeste da Torre 7, onde o revestimento argamassado apresentou uma espessura média de $7 \mathrm{~cm}$ e $8 \mathrm{~cm}$, respectivamente, evidenciando a necessidade das telas de reforço.

\section{Resultados e Discussões}

Foi realizado um furo no emboço de cada fachada estudada (Fig. 1) para que fosse possível encontrar as telas metálicas e realizar as leituras com o multímetro.

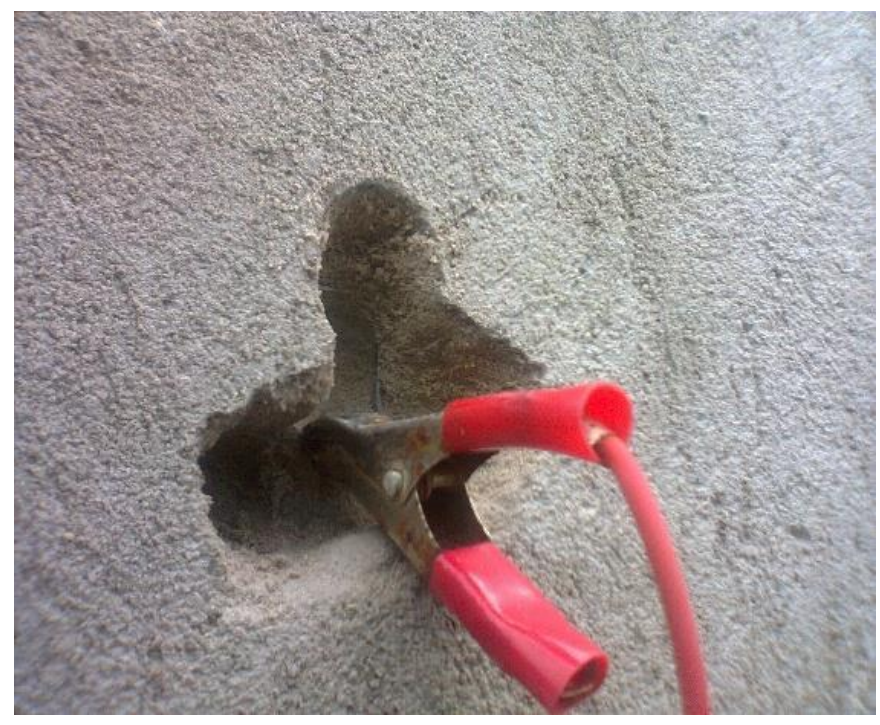

Figura 1: Gancho do multímetro na tela metálica galvanizada

Ao perfurar o emboço foi possível verificar uma boa aderência da tela com o revestimento e nenhum sinal visual de corrosão. Vale ressaltar que o revestimento analisado tinha 78 dias de aplicado e não apresentava fissuras na região onde as telas tinham sido posicionadas. Em cada furo foram realizadas 10 leituras (Tabela 4) e calculada a média para análise comparativa. 
Tabela 4: Leituras do multímetro para fachadas leste e oeste

\begin{tabular}{|c|c|c|c|c|}
\hline Ordem & $\begin{array}{l}\text { Leitura fachada } \\
\text { leste }(\mathrm{mV})\end{array}$ & $\begin{array}{l}\text { Média } \\
(\mathrm{mV})\end{array}$ & $\begin{array}{l}\text { Leitura fachada } \\
\text { oeste }(\mathrm{mV})\end{array}$ & $\begin{array}{c}\text { Média } \\
(\mathrm{mV})\end{array}$ \\
\hline $1^{0}$ & 18 & \multirow{10}{*}{12,8} & 14 & \multirow{10}{*}{7,3} \\
\hline $2^{0}$ & 14 & & 8 & \\
\hline $3^{0}$ & 15 & & 7 & \\
\hline $4^{\circ}$ & 16 & & 1 & \\
\hline $5^{0}$ & 16 & & 2 & \\
\hline $6^{\circ}$ & 14 & & 15 & \\
\hline $7^{0}$ & 12 & & 9 & \\
\hline $8^{\circ}$ & 5 & & 6 & \\
\hline 9o & 4 & & 8 & \\
\hline $10^{\circ}$ & 14 & & 3 & \\
\hline
\end{tabular}

A tela metálica posicionada na fachada leste está mais disposta às ações da chuva e do vento, portanto, o ensaio evidencia essa exposição. Porém, quando comparado aos critérios estabelecidos na norma [5], de modo geral, há apenas $10 \%$ de probabilidade de ocorrência de corrosão da tela.

\section{Conclusão}

Apesar de os ensaios terem sido realizados em apenas duas fachadas, uma amostra relativamente pequena, os dados coletados nesse trabalho são representativos. Pode-se concluir que as telas metálicas galvanizadas utilizadas nessa obra apresentam baixo potencial de corrosão de acordo com os requisitos da ASTM C876 , ainda que os critérios, ao qual foram comparados os resultados, se referirem ao aço carbono. Dessa forma, as telas garantem a aderência para qual foram projetadas, impedindo o surgimento de manifestações patológicas originadas a partir de espessuras elevadas de revestimento externo. Porém, se faz necessário um estudo mais amplo, analisando o desempenho do reforço quando as telas atingirem um prazo maior de aplicação. Apesar de pouca utilização no dia-a-dia dos canteiros de obra, a avaliação do potencial de corrosão das telas metálicas pode ser utilizada como ferramenta de ação preventiva para evitar maiores problemáticas com manutenções na fachada.

\section{Referências}

[1] NBR 13755 (1996) Revestimentos de paredes externas e fachadas com placas cerâmicas e com utilização de argamassa colante - Procedimento Associação Brasileira de Normas Técnicas - ABNT, Rio de Janeiro, Brasil.

[2] POLISSENI, A.E. (1986) Método de campo para avaliar a capacidade impermeabilizante de revestimentos de parede: método do cachimbo. $140 f$. Dissertação (Mestrado em engenharia) - Curso de pós-graduação em engenharia civil. Universidade Federal do Rio Grande do Sul, Porto Alegre, Brasil. 
[3] BAUER, L. A. F. (1994) Materiais de Construção // 5ª ed. LTC, Rio de Janeiro, Brasil.

[4] GENTIL, V. (2007) Corrosão. Escola de Química da Universidade Federal do

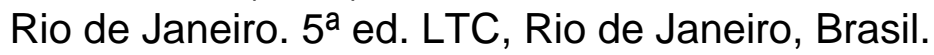

[5] ASTM C-876 (2009) Standard test method for half-cell potentials for uncoated reinforcing steel in concrete. In: Annual book of ASTM Standards. West Conshohocken, USA.

[6] PIANCA, F. SCHELL, H. (2005) The long term performance of three Ontario bridges constructed with galvanized reinforcement. MTO, Ontario Ministery of Transportation, Ontario, Canadá.

[7] SABBATINI, F.H. et al. (1998) Desenvolvimento tecnológico de métodos construtivos para alvenarias e revestimentos: recomendações para execução de revestimentos de argamassa para paredes de vedação e tetos. EPUSP-PCC, São Paulo, Brasil.

[8] NBR 13749 (2013) Revestimento de paredes e tetos de argamassa inorgânica - Especificação Associação Brasileira de Normas Técnicas - ABNT, Rio de janeiro, Brasil. 